\title{
Does Alcohol Consumption Affect Life Expectancy in OECD Countries?
}

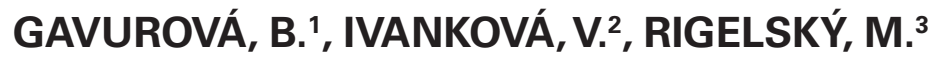

1 | Tomas Bata University in Zlín, Faculty of Management and Economics, Centre for Applied Economic Research, Zlín, Czech Republic

$2 \mid$ University of Prešov, Faculty of Management, Department of Economics and Economy, Prešov, Slovak Republic

3 | University of Prešov, Faculty of Management, Department of Marketing and International Trade, Prešov, Slovak Republic
Citation | Gavurová, B., Ivanková, V., Rigelský, M. (2020). Does Alcohol Consumption Affect Life Expectancy in OECD Countries? Adiktologie, 2013-4), 115-123; doi 10.35198/01-2020-002-0001
BACKGROUND: The consumption of different types of alcoholic beverages leads to different health risks. Therefore, different effects on the health of the population can be expected. AIM: The main objective of the study was to assess the relations between the consumption of selected types of alcoholic beverages and the life expectancy of the population in OECD countries. METHODS: Non-parametric analysis of relationships (Spearman $\rho$ ) and simple linear quartile regression analysis were used to meet the objective. SAMPLE: The research covered 36 countries of the Organisation for Economic Co-operation and Development (OECD). In the analytical procedures, four main types of alcoholic beverage were used: (i) beer, (ii) wine, (iii), spirits, (iv) other. The consumption of individual types of alcohol in each country was expressed in litres of pure alcohol per person (aged 15+ years) per year. The analysis also included a health variable determining life expectancy at birth. All data was collected for the period from 2010 to 2017. RESULTS: In terms of the consumption of common types of alcoholic beverages (beer, wine, spirits), a significant effect on life expectancy was found. Beer and spirits showed a negative effect, i.e. with increased consumption of beer and spirits, a decrease in life expectancy can be expected. On the other hand, wine consumption had a positive effect on life expectancy. A significant positive relationship was identified between the consumption of beer and of spirits, i.e. with an increase in the consumption of beer, an increase in the consumption of spirits can be expected. CONCLUSIONS: Prevention and education should focus in particular on the countries of Central and Eastern Europe, as higher consumption of beer and spirits was found in some of these countries. Lower alcohol consumption in these countries could have a positive effect on life expectancy.

\section{Keywords | Alcohol Risks - Beer - Wine - Spirits - Life Expectancy - OECD}

Grant affiliation | This research was supported by the Internal Grant Agency of the Faculty of Management and Economics of Tomas Bata University in Zlín: RVO/2020: "Economic quantification of marketing processes that focus on the increase in value for a patient in the process of the creation of a system to measure and control efficiency in health facilities in the Czech Republic". 


\section{INTRODUCTION AND THEORETICAL BACKGROUND}

Alcohol is one of the most common risk factors for harm to the health of the population, but it is part of everyday life. Alcohol consumption is a common social practice that society accepts, and therefore the issue of alcohol is overlooked in many cases, except in serious life-threatening situations (Ssebunnya et al., 2020). On the other hand, there is evidence that alcohol consumption has a negative effect on health (Kuntsche et al., 2017).

Alcohol is often an indirect cause of death, as alcohol consumption is a significant risk factor for fatal injuries, but also for serious diseases (Rehm et al., 2017). Many authors have confirmed that higher alcohol consumption causes a higher risk of cancer (Connor et al., 2017; Fedirko et al., 2011; Pelucchi et al., 2011), pneumonia (Simou et al., 2018a), liver cirrhosis (Roerecke et al., 2019), or tuberculosis (Simou et al., 2018b). There is also a risk of injury as a result of alcohol consumption, especially in women (Cherpitel et al., 2019). In terms of all-cause mortality, Stewart et al. (2017) found that heavier alcohol consumers have a higher risk of death compared to lighter alcohol consumers. The authors also highlighted that the risk of death is higher with a combination of heavy drinking and smoking. Similar findings were identified by Xu et al. (2007).

On the other hand, it is also possible to look at the issue of alcohol consumption from a mental health perspective. The findings of a study conducted by Hufford (2001) showed that excessive alcohol consumption, alcohol dependence, and negative events in life, but also comorbid psychopathology, are significant risk factors, which can be reflected in the suicidal behaviour of individuals. The author emphasized that alcohol plays an important role in this problem, as it increases mental distress and aggression, promotes suicidal thoughts, and reduces cognition (Hufford, 2001). Similar findings have been presented by many other authors, who found that alcohol is an important factor not only in suicides, but also self-harm behaviour (Amiri \& Behnezhad, 2020; Melson \& O'Connor, 2019; Norstrom \& Rossow, 2016). Darvishi et al. (2015) emphasized that alcohol use disorders are a predictor of suicidal behaviour and suicidal deaths, and therefore alcohol consumption is a significant source of premature mortality. Sher (2006) revealed that depression, aggression, impulsivity, or comorbid substances were identified in individuals with alcohol use disorders and suicidal behaviours. On this basis, the link between alcohol consumption, psychiatric disorders (such as psychosis, mood disorders, and anxiety disorders) and suicide, which is part of alcohol-related premature mortality, should be taken into account (Pompili et al., 2010).

When the health burden of alcohol consumption is being considered, the level of risk posed by different types of alcoholic beverages and the alcohol preferences in individual countries need to be taken into account. Benedetti et al. (2009) examined the relationship between alcoholic bev- erages and the risk of cancer, and the highest level of risk was identified in beer and spirits. On the other hand, the consumption of wine was associated with a reduced risk of venous thromboembolism (Hansen-Krone et al., 2011). Similarly, Gronbaek et al. (2000) underlined the beneficial effect of wine consumption in terms of all-cause mortality. This is consistent with the findings of Dey et al. (2014), who revealed that a preference for beer leads to a higher health risk compared to one for wine. The authors also argued that a preference for beer may be associated with an increase in the incidence of smoking or the consumption of illegal substances. In terms of spirits, Kerr et al. (2000) found that the consumption of spirits is more associated with mortality resulting from cirrhosis than is the case for beer and wine consumption.

All of the above-mentioned aspects can translate into an increase in alcohol-related mortality, and thus a reduction of life expectancy. Many authors have agreed that alcohol plays an important role in premature mortality (Leon et al., 2009; Zaridze et al., 2009). Simultaneously, alcohol consumption creates a health gap between different countries and alcohol represents a serious burden. In a study examining alcohol consumption in seven member states of the European Union (EU), Rehm et al. (2007) revealed that alcohol-related deaths are more frequent in the new EU member states (the Czech Republic, Hungary, Lithuania, and Poland) compared to the old EU member states (France, Sweden, and the United Kingdom), contributing to differences in life expectancy between these countries. At the same time, higher alcohol consumption was found in the old EU member states. According to Rehm and Probst (2018), the use of addictive substances, including alcohol, leads to the stagnation of life expectancy, and the effect was more significant in lower socio-economic groups compared to higher socio-economic groups. The negative effect of alcohol consumption on life expectancy was confirmed by Ranabhat et al. (2020); this effect was found in high-income and upper-middle-income countries, but no significant relationship was identified in low-income countries and lower-middle-income countries.

These findings confirm that alcohol consumption represents a serious health burden (Balakrishnan et al., 2009) and therefore needs to be addressed. This need is underlined by the fact that a healthy lifestyle, including lower alcohol consumption, has a positive effect on the health potential of the population, represented by life expectancy (Mehta \& Myrskyla, 2017). Therefore, the idea of the present study is to examine the relations between alcohol consumption in the classification of individual alcoholic beverages and life expectancy in developed countries in order to understand the issue of alcohol and to contribute to research efforts in this area.

\section{METHODOLOGY}

On the basis of the above-mentioned findings, it can be assumed that alcohol consumption has a negative effect on life expectancy. On the other hand, the effect of individual 
types of alcoholic beverages remains unanswered. Therefore, the main objective of the research in the present study was to assess the relations between the consumption of selected types of alcoholic beverages and the life expectancy of the population in OECD countries.

The first group of data (alcohol-related variables) was collected from the World Health Organization databases Global Health Observatory data repository (GHO, 2019) and analytical procedures included selected variables expressing alcohol consumption in litres of pure alcohol per capita (aged 15+ years) per year. Alcohol consumption was divided into four main categories of alcoholic beverages: (i) Beer barley beer 5\%; (ii) Wine - grape wine 12\%, grape must 9\%, vermouth 16\%; (iii) Spirits - distilled spirits 40\%, spirit-like $30 \%$; (iv) Other - sorghum, millet, maize beers 5\%, cider $5 \%$, fortified wine $17 \%$ and $18 \%$, fermented wheat and fermented rice $9 \%$, other fermented beverages $9 \%$. The health data of the second group included a health-related variable determining life expectancy at birth (LE), obtained from the databases of the Organisation for Economic Co-operation and Development (OECD, 2019). All data was collected for the period from 2010 to 2017 and 36 OECD countries (the number of member countries in 2019 when the data was collected) were included in the analytical procedures. The individual countries were abbreviated according to ISO 3166-1 (alpha-3): Australia - AUS, Austria - AUT, Belgium BEL, Canada - CAN, Czech Republic - CZE, Denmark - DNK, Estonia - EST, Finland - FIN, France - FRA, Germany - DEU, Greece - GRC, Hungary - HUN, Chile - CHL, Iceland - ISL, Ireland - IRL, Israel - ISR, Italy - ITA, Japan - JPN, South Korea - KOR, Latvia - LVA, Lithuania - LTU, Luxembourg LUX, Mexico - MEX, Netherlands - NDL, New Zealand- NZL, Norway - NOR, Poland - POL, Portugal - POR, Slovak Republic - SVK, Slovenia - SVN, Spain - ESP, Sweden - SWE, Switzerland - CHE, Turkey - TUR, United Kingdom - GBR, United States - USA.

The fulfilment of the main objective was carried out through analytical procedures, in which a descriptive analysis was used in the first step in order to point out the variables under analysis in more detail. This was followed by a relationship analysis using the Spearman correlation coefficient $\rho$. The last and most important part of the analytical processing included the application of regression analysis - Ordinary Least Squares quantile regression (OLS rq), which evaluated the significance of the effects of the consumption of individual types of alcoholic beverages. The effects were assessed using a quantile approach through the $5^{\text {th }}, 25^{\text {th }}, 50^{\text {th }}$, $75^{\text {th }}$, and $95^{\text {th }}$ percentiles.

\section{RESULT}

The following section of this study presents the outputs of analytical procedures that meet the main objective. This section was divided into three consecutive parts. At the beginning, descriptive analysis was applied, followed by relationship analysis, and finally the regression analysis of OLS rq was used.
Table 1 shows the outputs of the descriptive analysis and provides the basic characteristics of all the variables that were analysed for the period from 2010 to 2017. On the basis of the average values, the highest consumption can be identified in beer (mean $=3.74)$, followed by wine (mean $=2.78$ ), and spirits (mean $=2.13$ ), and the lowest consumption was found in other types of alcoholic beverages (mean $=0.59$ ). The above-mentioned average values of the alcohol-related variables represent litres of pure alcohol per person aged 15 years and over. Thus, in OECD countries, an average of 3.74 litres of beer and 0.59 litres of other alcohol per capita (aged 15+ years) were drunk annually. At the same time, the average life expectancy at birth in OECD countries during the period under analysis was 80.17 years. It is necessary to point out the skewness and kurtosis, which showed significant deviations from the normal distribution, especially in the category of other types of alcoholic beverages.

\begin{tabular}{lccccc}
\hline Stat & Beer & Wine & Spirits & Other & LE \\
\hline Mean & 3.74 & 2.78 & 2.13 & 0.59 & 80.17 \\
\hline Median & 3.80 & 2.86 & 1.76 & 0.12 & 81.10 \\
\hline Std. Dev. & 1.44 & 1.70 & 1.40 & 1.18 & 2.68 \\
\hline Min & 0.79 & 0.07 & 0.12 & 0.00 & 73.00 \\
\hline Max & 6.93 & 7.41 & 7.47 & 6.56 & 84.20 \\
\hline Skew & 0.05 & 0.31 & 1.38 & 3.51 & -1.02 \\
\hline Kurt & -0.56 & -0.16 & 2.11 & 13.84 & -0.05 \\
\hline
\end{tabular}

Table 1 | Descriptive statistics of the variables examined for the period from 2010 to 2017

Note: The alcohol-related variables are expressed in litres of pure alcohol per person (aged 15+ years) per year and the health-related variable is expressed in years. Source: original processing based on OECD (2019) and GHO (2019) data

Table 2 provides the average values of all variables for each OECD country in the period under analysis. The highest rate of beer consumption was found in the Czech Republic (mean = 6.83); on the other hand, Turkey reported the lowest beer consumption (mean $=0.85$ ) . Regarding the consumption of wine, France was the dominant country (mean = 7.12) and Israel was the country that preferred wine the least (mean $=0.10$ ). In terms of spirits, Estonia reported the highest consumption (mean $=6.57$ ) and the lowest consumption was observed in Mexico (mean $=0.20$ ). Focusing on the consumption of other types of alcoholic beverages, South Korea was the dominant country among OECD countries (mean $=6.38$ ); on the other hand, very low average consumption of other alcoholic beverages was found in several countries, such as Poland, Hungary, the Czech Republic, the United States, Chile, Luxembourg, Germany, Austria, the Netherlands, Iceland, Slovenia, Italy, and Turkey. In terms of the health-related variable, the highest life expectancy was identified in Japan (mean = 83.51) and the lowest value was found in Latvia (74.14). On the basis of these findings, the differences in alcohol consumption and alcohol preferences between OECD countries can be considered. These differences could be due to several aspects, such as culture, traditions, lifestyle, social habits, geographic location, and more. It is also possible to see that the average life expectancy in 
the countries that were analysed displayed a difference of almost more than nine years between the country with the highest value and the country with the lowest value. This is certainly a considerable difference, which can be assessed negatively, as the OECD includes developed countries, which should not create such a large gap in key attributes.

\begin{tabular}{|c|c|c|c|c|c|}
\hline ID & Beer & Wine & Spirits & Other & LE \\
\hline AUS & 4.04 & 3.79 & 1.27 & 0.87 & 82.26 \\
\hline AUT & 6.15 & 3.94 & 1.78 & 0.00 & 81.29 \\
\hline BEL & 4.69 & 3.74 & 1.40 & 0.25 & 80.98 \\
\hline CAN & 3.86 & 2.00 & 2.08 & 0.25 & 81.66 \\
\hline $\mathrm{CHE}$ & 3.14 & 4.61 & 1.79 & 0.12 & 83.09 \\
\hline $\mathrm{CHL}$ & 2.66 & 2.66 & 2.38 & 0.00 & 79.24 \\
\hline CZE & 6.83 & 2.72 & 3.19 & 0.00 & 78.50 \\
\hline DEU & 5.90 & 3.16 & 2.08 & 0.00 & 80.79 \\
\hline DNK & 3.59 & 4.42 & 1.57 & 0.08 & 80.43 \\
\hline EST & 5.60 & 2.05 & 6.57 & 1.90 & 77.13 \\
\hline FIN & 4.26 & 1.82 & 1.29 & 1.63 & 81.09 \\
\hline FRA & 2.15 & 7.12 & 2.51 & 0.22 & 82.36 \\
\hline GBR & 3.45 & 3.33 & 2.13 & 0.77 & 81.08 \\
\hline $\mathrm{GRC}$ & 2.06 & 3.44 & 1.50 & 0.09 & 81.14 \\
\hline HUN & 3.94 & 3.29 & 3.75 & 0.00 & 75.54 \\
\hline$\underline{I R L}$ & 5.17 & 2.86 & 2.11 & 0.86 & 81.30 \\
\hline ISL & 3.96 & 2.01 & 1.18 & 0.00 & 82.49 \\
\hline ISR & 1.50 & 0.10 & 1.15 & 0.05 & 82.09 \\
\hline ITA & 1.74 & 4.69 & 0.78 & 0.00 & 82.70 \\
\hline JPN & 1.35 & 0.25 & 2.59 & 2.65 & 83.51 \\
\hline KOR & 1.99 & 0.15 & 0.36 & 6.38 & 81.51 \\
\hline LTU & 5.34 & 1.24 & 5.45 & 1.98 & 74.34 \\
\hline LUX & 4.03 & 5.14 & 2.30 & 0.00 & 81.86 \\
\hline LVA & 4.82 & 1.19 & 4.08 & 0.64 & 74.14 \\
\hline MEX & 3.52 & 0.19 & 0.20 & 0.14 & 74.71 \\
\hline $\mathrm{NDL}$ & 4.19 & 3.01 & 1.43 & 0.00 & 81.46 \\
\hline NOR & 2.70 & 2.26 & 1.09 & 0.15 & 81.96 \\
\hline NZL & 3.44 & 3.04 & 1.49 & 1.17 & 81.40 \\
\hline $\mathrm{POL}$ & 5.71 & 0.88 & 3.81 & 0.00 & 77.31 \\
\hline POR & 2.66 & 5.93 & 1.38 & 0.37 & 80.88 \\
\hline SPN & 4.06 & 2.63 & 2.37 & 0.17 & 82.96 \\
\hline$\underline{\text { SVK }}$ & 3.42 & 2.32 & 4.29 & 0.44 & 76.58 \\
\hline SVN & 4.84 & 4.85 & 0.87 & 0.00 & 80.63 \\
\hline SWE & 2.65 & 3.43 & 1.03 & 0.12 & 82.10 \\
\hline TUR & 0.85 & 0.14 & 0.50 & 0.00 & 76.70 \\
\hline USA & 4.18 & 1.58 & 3.01 & 0.00 & 78.73 \\
\hline
\end{tabular}

Table 2 | Mean of selected variables in individual OECD countries for the period from 2010 to 2017

Note: In each column, the darker background represents higher (more negative) values for the alcohol-related variables and higher (more positive) values for the health-related variable. The alcohol-related variables are expressed in litres of pure alcohol per person (aged 15+ years) per year and the health-related variable is expressed in years.

Source: original processing based on OECD (2019) and GHO (2019) data
Table 3 points out the relationships between the variables that were analysed. As regards the relationship between alcohol consumption and life expectancy, the outputs in this correlation matrix show that life expectancy appears to be significantly associated with beer consumption, wine consumption, and the consumption of spirits. In the case of other alcoholic beverages, no significant relationship could be confirmed. The consumption of beer and spirits shows negative coefficients of relationships with life expectancy (Beer: $\rho=-0.393$; Spirits: $\rho=-0.357$ ), which can be interpreted as meaning that lower life expectancy may be associated with increased consumption of these types of alcoholic beverages. The opposite situation occurred in the relationship between wine consumption and life expectancy ( $\rho=0.309)$; in this case a positive coefficient can be seen. With a focus on the relationships between individual types of alcoholic beverages, significant relationships can be found between beer and spirits $(\rho=0.452)$, between beer and other alcoholic beverages ( $\rho=-0.121$ ), and between wine and other alcoholic beverages $(\rho=-0.213)$. A positive coefficient indicates that increased consumption of one type of alcoholic beverage may be associated with increased consumption of another type of alcoholic beverage. Conversely, a negative coefficient indicates that increased consumption of one type of alcoholic beverage may be associated with decreased consumption of another type of alcoholic beverage, and vice versa.

\begin{tabular}{lccccc}
\hline $\boldsymbol{\rho}$ & LE & Beer & Wine & Spirits & Other \\
\hline LE & & -0.393 & 0.309 & -0.357 & 0.076 \\
\hline Beer & $<0.001$ & & 0.047 & 0.452 & -0.121 \\
\hline Wine & $<0.001$ & 0.423 & & -0.055 & -0.213 \\
\hline Spirits & $<0.001$ & $<0.001$ & 0.354 & & 0.109 \\
\hline Other & 0.202 & 0.040 & $<0.001$ & 0.065 & \\
\hline
\end{tabular}

Table 3 Analysis of the relationships between the variables that were examined for the period from 2010 to 2017

Note: The highlighted cells in the table indicate the p-value and the strong significance of the relationship can be confirmed if its value is less than 0.001 . Source: original processing based on OECD (2019) and GHO (2019) data

Finally, Table 4 presents the output of the OLS rq application, in which the indicator of life expectancy was included as a dependent variable, and the consumption of individual types of alcoholic beverages (beer, wine, spirits, other) represents independent variables. It is necessary to emphasize the application of simple models; therefore, one independent variable was always used, according to which the applied regression models (QR Model) are named. The individual models were applied in five categories - in the $5^{\text {th }}, 25^{\text {th }}, 50^{\text {th }}, 75^{\text {th }}$, and $95^{\text {th }}$ percentiles $(\tau-$ tau) of life expectancy as a dependent variable. With a focus on the consumption of beer, a significant effect on life expectancy can be considered in all the categories of $\tau$ that were analysed. In the case of $\tau$ being equal to 0.05 , it is possible to see a tight limit value $(p$-value $=0.049)$. The regression coefficient $(\beta)$ is negative in all cases, indicating an inverse effect. The effect of wine consumption appears to be significant in the case 


\begin{tabular}{|c|c|c|c|c|c|c|c|c|c|c|c|}
\hline \multirow{2}{*}{$\begin{array}{l}\text { QR } \\
\text { Model }\end{array}$} & \multirow{2}{*}{$\begin{array}{c}\mathbf{T} \\
\text { Parameter }\end{array}$} & \multicolumn{2}{|c|}{0.05} & \multicolumn{2}{|c|}{0.25} & \multicolumn{2}{|c|}{0.5} & \multicolumn{2}{|c|}{0.75} & \multicolumn{2}{|c|}{0.95} \\
\hline & & $\alpha$ & $\beta$ & $\alpha$ & $\beta$ & $\alpha$ & $\beta$ & $\alpha$ & $\beta$ & $\alpha$ & $\beta$ \\
\hline \multirow[t]{4}{*}{ Beer } & Coefficient & 76.02 & -0.36 & 82.78 & -0.95 & 83.00 & -0.52 & 83.53 & -0.43 & 84.77 & -0.49 \\
\hline & Sig. & $<0.001$ & 0.049 & $<0.001$ & 0.001 & $<0.001$ & $<0.001$ & $<0.001$ & $<0.001$ & $<0.001$ & $<0.001$ \\
\hline & $95 \% \mathrm{Cl}$ LB & 74.58 & -0.72 & 80.48 & -1.52 & 82.17 & -0.73 & 83.04 & -0.55 & 84.03 & -0.68 \\
\hline & $95 \% \mathrm{Cl} \cup \mathrm{B}$ & 77.45 & 0.00 & 85.08 & -0.37 & 83.82 & -0.32 & 84.02 & -0.31 & 85.51 & -0.31 \\
\hline \multirow[t]{4}{*}{ Wine } & Coefficient & 72.21 & 1.32 & 75.51 & 0.99 & 79.86 & 0.36 & 81.76 & 0.09 & 83.37 & -0.08 \\
\hline & Sig. & $<0.001$ & $<0.001$ & $<0.001$ & $<0.001$ & $<0.001$ & 0.001 & $<0.001$ & 0.154 & $<0.001$ & 0.344 \\
\hline & $95 \% \mathrm{Cl}$ LB & 71.22 & 1.01 & 74.53 & 0.69 & 79.18 & 0.15 & 81.35 & -0.03 & 82.82 & -0.25 \\
\hline & $95 \% \mathrm{Cl} \cup \mathrm{B}$ & 73.21 & 1.62 & 76.49 & 1.29 & 80.54 & 0.57 & 82.16 & 0.22 & 83.92 & 0.09 \\
\hline \multirow[t]{4}{*}{ Spirits } & Coefficient & 74.84 & -0.15 & 82.74 & -1.48 & 83.55 & -1.48 & 83.30 & -0.87 & 83.20 & 0.00 \\
\hline & Sig. & $<0.001$ & 0.415 & $<0.001$ & $<0.001$ & $<0.001$ & $<0.001$ & $<0.001$ & $<0.001$ & $<0.001$ & 1.000 \\
\hline & $95 \% \mathrm{Cl}$ LB & 73.92 & -0.51 & 82.10 & -1.74 & 83.25 & -1.60 & 82.86 & -1.05 & 82.58 & -0.24 \\
\hline & $95 \% \mathrm{Cl} \cup \mathrm{B}$ & 75.75 & 0.21 & 83.39 & -1.23 & 83.84 & -1.37 & 83.74 & -0.70 & 83.82 & 0.24 \\
\hline \multirow[t]{4}{*}{ Other } & Coefficient & 74.64 & -0.29 & 78.70 & 0.23 & 81.10 & 0.05 & 82.00 & 0.06 & 82.96 & 0.36 \\
\hline & Sig. & $<0.001$ & 0.095 & $<0.001$ & 0.552 & $<0.001$ & 0.744 & $<0.001$ & 0.474 & $<0.001$ & $<0.001$ \\
\hline & $95 \% \mathrm{Cl}$ LB & 74.19 & -0.63 & 77.69 & -0.53 & 80.71 & -0.25 & 81.77 & -0.11 & 82.70 & 0.16 \\
\hline & $95 \% \mathrm{Cl} \cup \mathrm{B}$ & 75.09 & 0.05 & 79.71 & 1.00 & 81.49 & 0.34 & 82.23 & 0.24 & 83.21 & 0.55 \\
\hline
\end{tabular}

Table 4 | Quantile regression analysis of the variables that were examined for the period from 2010 to 2017

Source: original processing based on OECD (2019) and GHO (2019) data

of a lower life expectancy $(\tau=0.05,0.25,0.50)$. In the cases of a higher life expectancy $(\tau=0.75,0.95)$, it is not possible to confirm a significant effect of wine consumption on life expectancy. In all significant cases, a positive coefficient ( $\beta$ ) can be seen; therefore, a positive effect can be considered. Regarding the consumption of spirits, a significant effect on life expectancy can be found if $\tau=0.25-0.75$. The regression coefficient $(\beta)$ is negative in all significant cases, indicating an inverse effect, as in the case of beer consumption. Focusing on the consumption of other types of alcoholic beverages, a significant effect on life expectancy can be seen only in the category of $\tau=0.95$, which represents the category with the highest life expectancy. In this case, a positive effect is evident $(\beta=0.36)$.

Figure 1 visualizes the effects found in Table 4. The highest level of emphasis can be attributed to those categories in which $\tau$ (tau) is in the range from 0.25 to 0.75 . Thus, other alcoholic beverages cannot be considered as a type of alcohol with a significant effect compared to beer and spirits, which have a negative coefficient. A positive significant effect on life expectancy can be attributed to wine consumption.

\section{DISCUSSION}

The main objective of the study was to assess the relations between the consumption of selected types of alcoholic beverages and the life expectancy of the population in OECD countries. This objective was fulfilled through several analytical procedures. In the first step, descriptive analysis was used, which pointed to the level of life expectancy and alcohol consumption in OECD countries as a whole, but also in the individual countries that were analysed.
The description of the variables that were included in the analyses was very important for the overall understanding of the issue under examination. In OECD countries, an average of 3.74 litres of beer, 2.78 litres of wine, 2.13 litres of spirits, and 0.59 litres of other alcoholic beverages per person (aged 15+ years) were drunk annually. Thus, the highest rate of alcohol consumption was found for beer and the lowest consumption was identified in the case of other types of alcoholic beverages. At this point, it should be noted that beer consumption appears to be the riskiest from a health point of view (Benedetti et al., 2009; Dey et al., 2014). In terms of individual countries, it can be concluded that alcohol consumption was more frequent in the countries of Central and Eastern Europe, where beer and spirits were preferred. This finding is consistent with the results of a study conducted by Rehm et al. (2007), who examined the level of alcohol consumption in seven EU countries. These authors revealed that alcohol-related deaths were more frequent in the Czech Republic, Hungary, Lithuania, and Poland than in the United Kingdom, France, and Sweden. In the present study, these disadvantaged countries also showed a lower life expectancy. The level of alcohol consumption and the preferences for alcoholic beverages can play an important role in these differences (Trias-Llimos et al., 2018). The level of alcohol consumption, as well as the preferences for individual types of alcoholic beverages, can be explained by culture, religion, history, geographical location, or social habits. These aspects can affect the level of acceptability of alcohol in society, which can be seen when one compares Turkey and the Czech Republic or Estonia. The structure and the preferences for alcohol are determined mainly by the history and geographical location of the country, which can be seen in the case of France. 

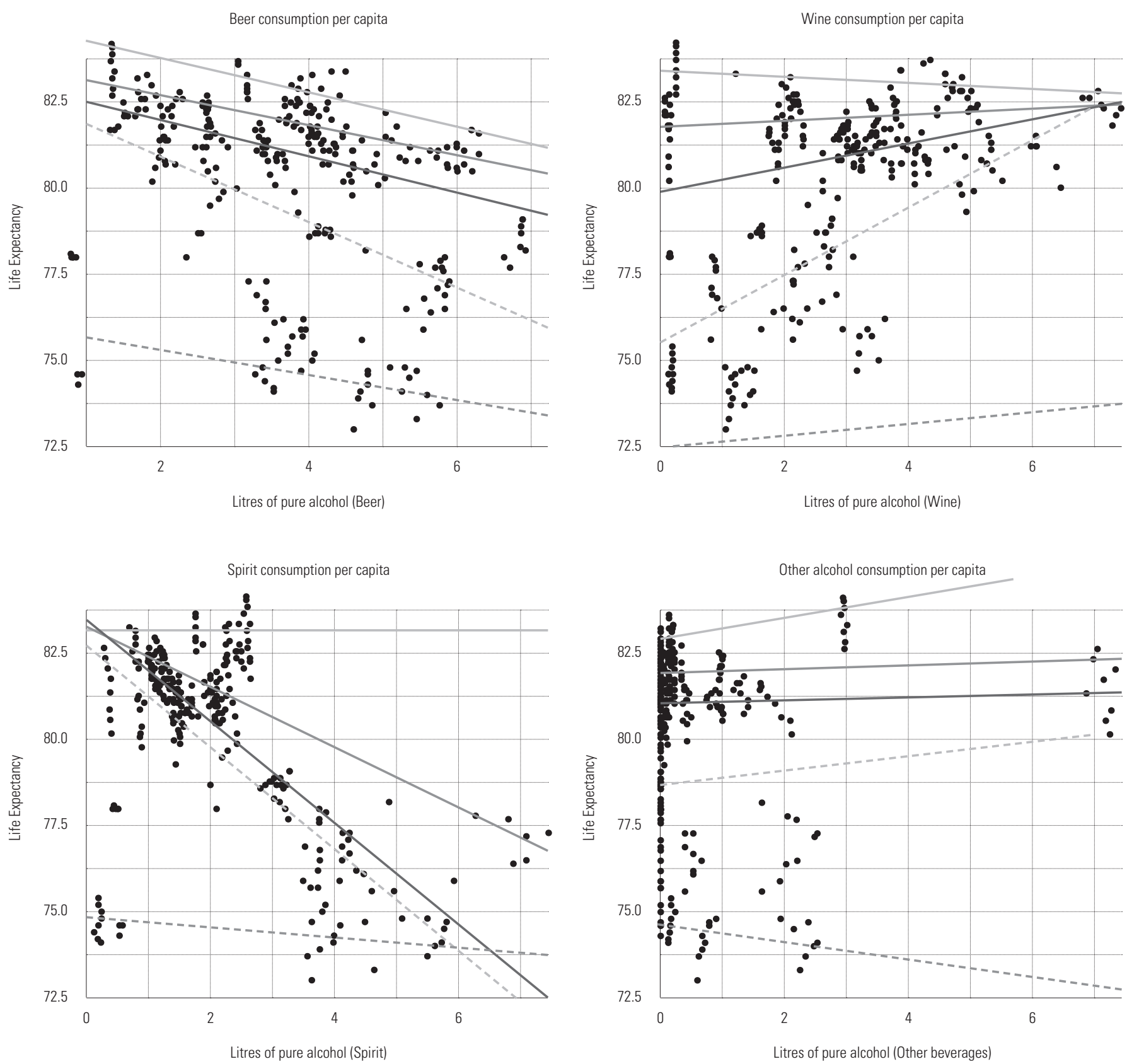

quantile

Figure 1 | Visualization of effects

Source: original processing based on OECD (2019) and GHO (2019) data

After the level and the preferences regarding alcohol consumption in OECD countries had been identified, the analysis of the relationships between the consumption of individual types of alcoholic beverages and the life expectancy of the population was applied. This analysis pointed to the associations between the health-related variable and the individual alcohol-related variables, as well as between the alcohol-related variables themselves. The outputs of this analysis showed that a decrease in life expectancy can be associated with an increase in the consumption of beer and spirits. In the case of wine con- sumption, the rate of association was lower, but it was positive. Therefore, increased life expectancy may be associated with increased wine consumption. On the basis of the above-mentioned findings, the preference for wine can be assessed more positively than the preference for beer and spirits. The relationship analysis also pointed to the fact that there is a significant positive relationship between the consumption of beer and that of spirits. Therefore, it can be concluded that with an increase in the consumption of beer, an increase in the consumption of spirits can be expected. 
The application of regression analysis pointed to the statistical significance of the effects of the consumption of individual types of alcoholic beverages on life expectancy divided into the categories of the $5^{\text {th }}, 25^{\text {th }}, 50^{\text {th }}, 75^{\text {th }}$, and $95^{\text {th }}$ percentiles. In determining the effect of beer consumption on life expectancy, it can be concluded that all the categories that were evaluated were significant (this statement should be taken with caution for the category with the lowest life expectancy, in which the significance was demonstrated very closely). All significant cases show a negative coefficient, which means the inverse effect of beer consumption on life expectancy, i.e. with increased beer consumption, a decrease in life expectancy can be expected. This is in line with the findings revealed by Benedetti et al. (2009) or Dey et al. (2014), who emphasized that consumers with a preference for beer face a higher health risk, and thus beer consumption is harmful to health. When the effect of wine consumption is assessed, the positive effect can be confirmed in several cases. Thus, an increase in wine consumption can lead to an increase in life expectancy - this can be confirmed in the case of countries with a lower-to-medium life expectancy. This is consistent with the findings of HansenKrone et al. (2011) or Gronbaek (2000), who argued that wine consumption could be beneficial to health. The effect of the consumption of spirits was found in the three analysed categories of life expectancy $\left(25^{\text {th }}, 50^{\text {th }}\right.$ and $75^{\text {th }}$ percentiles), with the exception of the categories with the highest and the lowest life expectancy ( $5^{\text {th }}$ and $95^{\text {th }}$ percentiles). The regression coefficient was negative in all significant cases, indicating an inverse effect, i.e. increased consumption of spirits can lead to a decrease in life expectancy. At this point, it is necessary to mention the findings of Benedetti et al. (2009), who highlighted that the consumption of spirits leads to health risks. Kerr et al. (2000) also confirmed the association between the consumption of spirits and mortality resulting from cirrhosis. In the case of the consumption of other types of alcoholic beverages, it is not possible to confirm significant effects in four out of five cases. The only significant effect and, simultaneously, a positive effect was found in the category with the highest life expectancy. In interpreting these assumptions, it is appropriate to place the greatest emphasis on the three middle categories, i.e. the 25th, 50th, and 75th percentiles. Overall, the outputs of this study confirmed the fact that alcohol consumption has a negative effect on life expectancy, consistently with the findings of Rehm and Probst (2018) and Ranabhat et al. (2020).

\section{CONCLUSION}

In general, alcohol consumption appears to be a serious health problem threatening the population (Balakrishnan et al., 2009). Nevertheless, alcohol is very popular and accepted in the world and it can be said that this problem is overlooked in many communities. On the other hand, the negative effects of alcohol are well known (Connor et al., 2017; Rehm et al., 2017; Roerecke et al., 2019; Simou et al., 2018a, 2018b; Stewart et al., 2017). Simultaneously, it can be concluded that alcohol plays an important role in premature mortality (Leon et al., 2009; Rehm et al., 2007; Zaridze et al., 2009), which can also be reflected in life expectancy. All these facts underline the importance of the issue of alcohol consumption and support the efforts to examine the relations between alcohol consumption and health potential. Therefore, this study contributes to the understanding of these relations in terms of alcohol consumption and life expectancy.

Accordingly, the main objective of the research in the present study was to assess the relations between the consumption of selected types of alcoholic beverages and the life expectancy of the population in OECD countries. This objective was achieved by descriptive analysis, relationship analysis, and regression analysis, which formed a set of subsequent analytical procedures. This analytical processing provided a comprehensive picture of the issue under examination, emphasizing the current situation in the consumption of individual alcoholic beverages in OECD countries, as well as the effects of alcohol consumption on life expectancy. As a result, this study confirmed the fact that alcohol consumption has a negative effect on life expectancy. With a focus on individual alcoholic beverages, a positive effect of wine consumption can be found in countries with a low life expectancy. On the other hand, the consumption of beer and spirits appears to be a risk factor for health. It can be concluded that a decrease in life expectancy may be related to increased consumption of beer and spirits among the population.

On the basis of these findings, it is possible to emphasize the need for prevention and education in the area of alcohol consumption (Allamani, 2012). In the context of the health potential of the population, providing assistance to alcohol addicts and mentally ill individuals can be one of many effective ways. Mental health programmes must take into account drinking habits, as alcohol consumption plays an important role in suicidal behaviour, which contributes to an increase in premature mortality and a reduction of life expectancy. Society as a whole should pay attention to alcohol prevention programmes that promote healthy behaviour. The efforts of prevention and education organizations should focus in particular on consumers of beer and spirits, as these types of alcohol are high-risk and frequent. The consumption of these types of alcoholic beverages seems to be problematic (excessive) in most countries of Eastern and Central Europe. Public policies can also be very powerful and effective through high prices, taxes, and a ban on alcohol promotion. In any case, policy makers need to address this issue in order to improve the health potential of the population and intervention strategies are necessary to control alcohol consumption.

The limitations of the study are represented by the fact that the data also includes the consumption of alcoholic beverages by people other than citizens of the country in question (tourism, migration); therefore, the outputs could be affected, but this effect cannot be expected to be significant. Many aspects that affect life expectancy, for example, cultural, religious, historical, and socio-economic factors, can 
be considered. These aspects can be linked not only to life expectancy, but also to attitudes to, and acceptance of, alcohol consumption. Other limitations include the fact that this research does not take into account the gender classification in terms of alcohol consumption, as well as in terms of life expectancy in OECD countries. On this basis, it can be assumed that the effects that are analysed may differ between women and men. Last but not least, a certain limitation is that the research focuses on the issue from a pointof-time perspective, which necessarily changes over time. These facts will encourage research activities in this area in the future.
Further research will focus on examining the relations between alcohol consumption in the classification of individual alcoholic beverages and other health indicators. The future research will also include variables (cultural, socio-economic) that may affect the relations that are analysed. The gender characteristics of the population will also be taken into account.
Authors' contribution: Conceptualisation: Beáta Gavurová; Data curation: Martin Rigelský; Methodology: Martin Rigelský; Formal analysis: Martin Rigelský; Results: Viera Ivanková; Visualisation: Beáta Gavurová and Viera Ivanková; Final edition: Beáta Gavurová, Martin Rigelský and Viera Ivanková. All authors have read and agreed to the published version of the manuscript.
Declaration of interest: Authors declare that they do not have any competing financial, professional, or personal interests from other parties.

\section{REFERENCES}

Allamani, A. (2012). Alcohol consumption policies and the prevention of alcohol consumption-related problems: needs, duties, and responsibilities. Substance Use \& Misuse, 47(12), 1252-1259. http://doi.org/10.3109/10826084.2012.716483

Amiri, S., \& Behnezhad, S. (2020). Alcohol use and risk of suicide: a systematic review and meta-analysis. Journal of Addictive Diseases, 38(2), 200-213. http://doi.org/10.1080/10550887.2020.1736757

Balakrishnan, R., Allender, S., Scarborough, P., Webster, P., \& Rayner, M. (2009). The burden of alcohol-related ill health in the United Kingdom. Journal of Public Health, 31(3), 366-373. http://doi.org/10.1093/pubmed/fdp051

Benedetti, A., Parent, M. E., \& Siemiatycki, J. (2009). Lifetime consumption of alcoholic beverages and risk of 13 types of cancer in men: Results from a case-control study in Montreal. Cancer Detection and Prevention, 32(5-6), 352-362. http://doi.org/10.1016/j.canep.2009.03.001

Cherpitel, C. J., Ye, Y., \& Monteiro, M. G. (2019). Dose-response relative risk of injury from acute alcohol consumption in 22 countries: are women at higher risk than men? Alcohol and Alcoholism, 54(4), 396-401.

http://doi.org/10.1093/alcalc/agz018

Connor, J., Kydd, R., Maclennan, B., Shield, K., \& Rehm, J. (2017). Alcoholattributable cancer deaths under 80 years of age in New Zealand. Drug and Alcohol Review, 36(3), 415-423. http://doi.org/10.1111/dar.12443

Darvishi, N., Farhadi, M., Haghtalab, T., \& Poorolajal, J. (2015). Alcohol-related risk of suicidal ideation, suicide attempt, and completed suicide: a metaanalysis. Plos One, 105), e0126870.

http://doi.org/10.1371/journal.pone.0126870

Dey, M., Gmel, G., Studer, J., Dermota, P., \& Mohler-Kuo, M. (2014). Beverage preferences and associated drinking patterns, consequences and other substance use behaviours. European Journal of Public Health, 24(3), 496-501. http://doi.org/10.1093/eurpub/ckt109

Fedirko, V., Tramacere, I., Bagnardi, V., Rota, M., Scotti, L., Islami, F., Negri, E., Straif, K., Romieu, I., La Vecchia, C., Boffetta, P., \& Jenab, M. (2011). Alcohol drinking and colorectal cancer risk: an overall and dose-response meta-analysis of published studies. Annals of Oncology, 22(9), 1958-1972. http://doi.org/10.1093/annonc/mdq653

GHO. (2019). World Health Organization databases - Global Health Observatory data repository. Available at: https://www.who.int/gho/database/en/
Gronbaek, M., Becker, U., Johansen, D., Gottschau, A., Schnohr, P., Hein, H. O., Jensen, G., \& Sorensen, T. I. A. (2000). Type of alcohol consumed and mortality from all causes, coronary heart disease, and cancer. Annals of Internal Medicine, 133(6), 411-419. http://doi.org/10.7326/0003-4819-133-6-200009190-00008

Hansen-Krone, I. J., Braekkan, S. K., Enga, K. F., Wilsgaard, T., \& Hansen, J. B. (2011). Alcohol consumption, types of alcoholic beverages and risk of venous thromboembolism - the Tromsø study. Thrombosis and Haemostasis, 106(2), 272-278. http://doi.org/10.1160/TH11-01-0043

Hufford, M. R. (2001). Alcohol and suicidal behavior. Clinical Psychology Review, 21(5), 797-811. http://doi.org/10.1016/S0272-7358(00)00070-2

Kerr, W. C., Fillmore, K. M., \& Marvy, P. (2000). Beverage-specific alcohol consumption and cirrhosis mortality in a group of English-speaking beer-drinking countries. Addiction, 95(3), 339-346.

http://doi.org/10.1046/j.1360-0443.2000.9533394.x

Kuntsche, E., Kuntsche, S., Thrul, J., \& Gmel, G. (2017). Binge drinking: health impact, prevalence, correlates and interventions. Psychology \& Health, 32(8), 976-1017. http://doi.org/10.1080/08870446.2017.1325889

Leon, D. A., Shkolnikov, V. M., \& McKee, M. (2009). Alcohol and Russian mortality: a continuing crisis. Addiction, 104(10), 1630-1636. http://doi.org/10.1111/j.1360-0443.2009.02655.x

Mehta, N., \& Myrskyla, M. (2017). The population health benefits of a healthy lifestyle: life expectancy increased and onset of disability delayed. Health Affairs, 36(8), 1495-1502. http://doi.org/10.1377/hlthaff.2016.1569

Melson, A. J., \& O'Connor, R. C. (2019). Differentiating adults who think about self-harm from those who engage in self-harm: the role of volitional alcohol factors. BMC Psychiatry, 19(1), 319. http://doi.org/10.1186/s12888-019-2292-3

Norstrom, T., \& Rossow, I. (2016). Alcohol consumption as a risk factor for suicidal behavior: a systematic review of associations at the individual and at the population level. Archives of Suicide Research, 2044), 489-506. http://doi.org/10.1080/13811118.2016.1158678

OECD. (2019). Organisation for Economic Co-operation and DevelopmentHealth Status: Life expectancy. Available at: https://stats.oecd.org/

Pelucchi, C., Tramacere, I., Boffetta, P., Negri, E., \& La Vecchia, C. (2011). Alcohol consumption and cancer risk. Nutrition and Cancer-An International Journal, 63(7), 983-990. http://doi.org/10.1080/01635581.2011.596642 
Pompili, M., Serafini, G., Innamorati, M., Dominici, G., Ferracuti, S., Kotzalidis, G. D., Serra, G., Girardi, P., Janiri, L., Tatarelli, R., Sher, L., \& Lester, D. (2010). Suicidal behavior and alcohol abuse. International Journal of Environmental Research and Public Health, 74), 1392-1431. http://doi.org/10.3390/ijerph7041392

Ranabhat, C. L., Park, M. B., \& Kim, C. B. (2020). Influence of alcohol and red meat consumption on life expectancy: results of 164 countries from 1992 to 2013. Nutrients, 12(2), 459. http://doi.org/10.3390/nu12020459

Rehm, J., Gmel, G. E., Gmel, G., Hasan, O. S. M., Imtiaz, S., Popova, S., Probst, C., Roerecke, M., Room, R., Samokhvalov, A. V., Shield, K. D., \& Shuper, P. A. (2017). The relationship between different dimensions of alcohol use and the burden of disease - an update. Addiction, 112(6), 968-1001. http://doi.org/10.1111/add.13757

Rehm, J., \& Probst, C. (2018). Decreases of life expectancy despite decreases in non-communicable disease mortality: the role of substance use and socioeconomic status. European Addiction Research, 24(2), 53-59. http://doi.org/10.1159/000488328

Rehm, J., Sulkowska, U., Manczuk, M., Boffetta, P., Powles, J., Popova, S., \& Zatonski, W. (2007). Alcohol accounts for a high proportion of premature mortality in Central and Eastern Europe. International Journal of Epidemiology, 36(2), 458-467. http://doi.org/10.1093/ije/dyl294

Roerecke, M., Vafaei, A., Hasan, O. S. M., Chrystoja, B. R., Cruz, M., Lee, R., Neuman, M. G., \& Rehm, J. (2019). Alcohol consumption and risk of liver cirrhosis: a systematic review and meta-analysis. American Journal of Gastroenterology, 114(10), 1574-1586. http://doi.org/10.14309/ajg.0000000000000340

Sher, L. (2006). Alcoholism and suicidal behavior: a clinical overview. Acta Psychiatrica Scandinavica, 113(1), 12-22. http://doi.org/10.1111/j.1600-0447.2005.00643.x

Simou, E., Britton, J., \& Leonardi-Bee, J. (2018a). Alcohol and the risk of pneumonia: a systematic review and meta-analysis. BMJ Open, 8(8), e022344. http://doi.org/10.1136/bmjopen-2018-022344

Simou, E., Britton, J., \& Leonardi-Bee, J. (2018b). Alcohol consumption and risk of tuberculosis: a systematic review and meta-analysis. International Journal of Tuberculosis and Lung Disease, 22(11), 1277-1285. http://doi.org/10.5588/ijtld.18.0092

Ssebunnya, J., Kituyi, C., Nabanoba, J., Nakku, J., Bhana, A., \& Kigozi, F. (2020). Social acceptance of alcohol use in Uganda. BMC Psychiatry, 2011), 52. http://doi.org/10.1186/s12888-020-2471-2

Stewart, D., Han, L., Doran, T., \& McCambridge, J. (2017). Alcohol consumption and all-cause mortality: an analysis of general practice database records for patients with long-term conditions. Journal of Epidemiology and Community Health, 71(8), 729-735. http://doi.org/10.1136/jech-2017-209241

Trias-Llimos, S., Kunst, A. E., Jasilionis, D., \& Janssen, F. (2018). The contribution of alcohol to the east-west life expectancy gap in Europe from 1990 onward. International Journal of Epidemiology, 47(3), 731-739. http://doi.org/10.1093/ije/dyx244

Xu, W. H., Zhang, X. L., Gao, Y. T., Xiang, Y. B., Gao, L. F., Zheng, W., \& Shu, X. 0. (2007). Joint effect of cigarette smoking and alcohol consumption on mortality. Preventive Medicine, 45(4), 313-319. http://doi.org/10.1016/j.ypmed.2007.05.015

Zaridze, D., Brennan, P., Boreham, J., Boroda, A., Karpov, R., Lazarev, A., Konobeevskaya, I., Igitov, V., Terechova, T., Boffetta, P., \& Peto, R. (2009). Alcohol and cause-specific mortality in Russia: a retrospective case-control study of 48557 adult deaths. Lancet, 373(9682), 2201-2214. http://doi.org/10.1016/S0140-6736(09)61034-5 